\title{
Populações microbianas e componentes nutricionais nos órgãos do capim-tanzânia antes e após a ensilagem
}

\section{Microbial population and nutritional compounds in the organs of tanzania-grass before and after ensilage}

\author{
Anderson de Moura Zanine ${ }^{1 *}$; Edson Mauro Santos ${ }^{1}$; \\ Daniele de Jesus Ferreira²; Odilon Gomes Pereira ${ }^{3}$
}

\section{Resumo}

Este experimento foi conduzido com o objetivo de avaliar as populações microbianas e o valor nutricional dos diferentes órgãos das plantas do capim-tanzânia (Panicum maximum) antes e após a ensilagem. Foram coletadas dez amostras do pasto, ao acaso com o uso de um quadrado de $1 \mathrm{~m}^{2}$. Foram feitos as separações botânica das folhas em expansão, folhas expandidas, folhas senescente, colmo e a planta inteira. Foram efetuadas contagens de microrganismos e o valor nutricional dos diferentes órgãos da planta. Determinou-se o número de bactérias láticas, enterobactérias, fungos e leveduras e os valores de matéria seca, proteína bruta, fibra em detergente neutro, fibra em detergente ácido e hemicelulose. As populações microbianas foram variáveis em função do órgão da planta, e o colmo foi o órgão que assegurou o crescimento de bactérias láticas e inibição do crescimento de microrganismos indesejáveis durante a ensilagem do capim-tanzânia. No âmbito nutricional, existiu uma hierarquia decrescente do valor bromatológico: folha em expansão, folha expandida, planta inteira e colmo antes e após o processo de ensilagem.

Palavras-chave: Ácido lático, bactéria, colmo, folha, silagem, valor nutricional

\begin{abstract}
This experiment was carried with the objective of evaluating the microbial populations and the nutritional value of different organs of plants of the tanzânia-grass (Panicum maximum) before and after the ensilage. Ten samples were collected at random at the pasture with the use of a square of $1 \mathrm{~m}^{2}$, were taken the botanical separation of the leaves in expansion, expanded leaves, leaves senesce, stem and the plant. Counting of microorganisms and the nutritional value were made in the different organs of the plant. Was determined the number of lactic bacterium, enterobacterium, fungi and yeasts and dry matter values, crude protein, neutral detergent fiber, acid detergent fiber and hemicellulose. The microbial populations were variable in function of the organ of the plant, and the stem is the organ that assures the growth of lactic bacteria and inhibition of growth of undesirable microorganisms during the ensilage of the tanzâniagrass. In the nutritional extent, a decreasing hierarchy of the value bromatológic exists: leafs in expansion, expanded leaf, plant completes and stem before and after the ensilage process.
\end{abstract}

Key words: Bacterium, lactic acid, leaf, nutritional value, silage, stem

1 Doutorando em Zootecnia, Universidade Federal de Viçosa-UFV, E-mail: anderson.zanine@ibest.com.br

2 Graduanda em Zootecnia, Universidade Federal Rural do Rio de Janeiro-UFRRJ, Rio de Janeiro, RJ.

3 Professor Adjunto do Departamento de Zootecnia, Universidade Federal de Viçosa-UFV, Viçosa, MG.

* Autor para correspondência

Recebido para publicação 05/06/06 Aprovado em 12/01/07 


\section{Introdução}

É indiscutível o papel da silagem como volumoso suplementar na alimentação de ruminantes em período de escassez de forragem. A silagem de capim vem surgindo como uma alternativa às culturas tradicionais, tendo como vantagens as características de uma cultura perene, possibilidade de suportar elevadas lotações na propriedade e apresenta grande flexibilidade em manejo na tomada de decisão (IGARASI, 2002).

Ensilagem é o método de preservação para forragens úmidas. É baseado na conversão de carboidratos solúveis em ácidos orgânicos, principalmente ácido lático, por bactérias ácidoláticas. Como resultado, há uma redução do $\mathrm{pH}$ e o material, ainda úmido, torna-se livre da ação de microrganismos indesejáveis (como as enterobactérias, fungos e leveduras), podendo ser fornecido aos animais, nos períodos de maior escassez de forragem (MCDONALD; HENDERSON; HERON, 1991; WRIGHT et al., 2000; FILYA; SUCU; KARABULUT, 2004).

Entre as cultivares da espécie Panicum maximum Jacq., o capim-tanzânia vem ganhando destaque em razão de sua alta produção de massa verde (ÁVILA et al., 2003). Jank (1994) obtiveram, para o capimtanzânia, uma produção de 133 t/ha/ano de massa verde e uma produção de matéria seca de 33 t/ha. Esses valores mostram a capacidade produtiva dessa gramínea.

Por conseguinte, o uso do excedente da produção de capins nas épocas favoráveis pode ser na forma de silagem. Entretanto, o elevado teor de umidade e a baixa concentração de carboidratos solúveis favorecem o crescimento de microrganismos indesejáveis, que resultam em perdas de nutrientes (MCDONALD， 1981; WOOLFORD， 1984; WEISSBACH; MUCK, 1996). É recomendável, durante a ensilagem de gramíneas, que seja aproveitado o colmo das plantas, devido ao seu elevado teor de matéria seca e grande quantidade de carboidratos de reserva. Desta forma, espera-se que ocorra, neste órgão, um elevado número de bactérias produtoras de ácido lático, bem como uma quantidade reduzida de enterobactérias, fungos e leveduras e se manejado corretamente poderá apresentar valor nutricional considerável.

Assim, objetivou-se verificar possíveis diferenças na população microbiana e no valor nutricional nos diferentes órgãos da planta e na planta inteira, antes e após a ensilagem do capim-tanzânia.

\section{Material e Métodos}

O experimento foi realizado no Departamento de Zootecnia da Universidade Federal de Viçosa, localizada no município de Viçosa-MG. A cidade de Viçosa está situada a $20^{\circ}$ e $45^{\prime}$ de latitude sul, $42^{\circ}$ e 51 'de longitude oeste e $657 \mathrm{~m}$ de altitude, apresentando precipitação média anual de $1341 \mathrm{~mm}$, dos quais cerca de $86 \%$ ocorrem nos meses de outubro a março.

Foi utilizada uma pastagem de capim-tanzânia (Panicum maximum), recém formada com 60 dias de rebrotação após pastejo por bovinos. Os valores das características químicas do solo podem ser observados na Tabela 1. Não houve necessidade de se fazer qualquer tipo de correção ou adubação da área para o plantio da gramínea, tendo em vista a grande fertilidade apresentada pelo solo da área, bem como pelo alto valor do $\mathrm{pH}$ e o baixo valor do alumínio. Apenas utilizou-se $50 \mathrm{~kg} / \mathrm{ha}$ de nitrogênio após o pastejo.

Foram realizadas ao acaso, 10 amostragens da forragem, sendo retiradas amostras em uma área de $1 \mathrm{~m}^{2}$. Destas amostras, determinou-se a relação folha em expansão:folha expandida:colmo, que foi de 28,61:35,17:36,21, respectivamente. As amostras foram levadas ao Laboratório de Forragicultura e Pastagens do Departamento de Zootecnia, para serem efetuadas contagens de microrganismos nas diferentes partes da planta (folha em expansão, folha expandida, folha senescente e colmo) e na planta inteira. 
Tabela 1. Características químicas das amostras da camada $(0-20$ e 20-40 cm) do solo da área experimental.

\begin{tabular}{lcc}
\hline \multirow{2}{*}{ Características químicas } & \multicolumn{2}{c}{ Resultados } \\
\cline { 2 - 3 } & $0-20 \mathrm{~cm}$ & $20-40 \mathrm{~cm}$ \\
\hline $\mathrm{pH}\left(\mathrm{H}_{2} \mathrm{O}\right)$ & 6,6 & 6,6 \\
Cálcio $\left(\mathrm{cmol}_{\mathrm{c}} / \mathrm{dm}^{3}\right)$ & 4,9 & 4,5 \\
Magnésio $\left(\mathrm{cmol}_{\mathrm{c}} / \mathrm{dm}^{3}\right)$ & 1,1 & 0,9 \\
Alumínio $\left(\mathrm{cmol}_{\mathrm{c}} / \mathrm{dm}^{3}\right)$ & 0,0 & 0,0 \\
$\mathrm{H}+\mathrm{Al}\left(\mathrm{cmol}_{\mathrm{c}} / \mathrm{dm}^{3}\right)$ & 1,65 & 1,65 \\
$\mathrm{CTC}\left(\mathrm{cmol}_{\mathrm{c}} / \mathrm{dm}^{3}\right)$ & 9,57 & 7,69 \\
$\mathrm{CTC}$ efetiva $\left(\mathrm{cmol}_{\mathrm{c}} / \mathrm{dm}^{3}\right)$ & 7,92 & 6,04 \\
Saturação de bases $(\%)$ & 83 & 79 \\
Fósforo - Mehlich-1 $\left(\mathrm{mg} / \mathrm{dm}^{3}\right)$ & 53,4 & 32,3 \\
Potássio - Mehlich-1 $\left(\mathrm{mg} / \mathrm{dm}^{3}\right)$ & 360 & 250 \\
\hline
\end{tabular}

*Capacidade de troca cátion-iônica.

Para a avaliação microbiana foram utilizados 10 g de amostra diluídas em $90 \mathrm{ml}$ de solução tampão fosfato de maneira a se obter uma diluição de $10^{-1}$. Em seguida, foram efetuadas diluições que variaram de $10^{-1}$ a $10^{-9}$. Para a contagem de bactérias láticas foi utilizado o meio de cultura Ágar Rogosa (Difico); para contagem de enterobactérias, utilizou-se o meio de cultura Violet Red Bile e para contagem de fungos e leveduras, utilizou-se o meio de cultura Batata Dextrose Ágar. Foram consideradas passíveis de contagens, placas contendo entre 30 e 300 ufc (unidade formadora de colônia). O restante das amostras das diferentes partes da planta e da planta inteira foram cortadas a $2 \mathrm{~cm}$ e ensiladas em minissilos de vidro, com capacidade para $1000 \mathrm{ml}$. Quarenta e cinco dias após, os minissilos foram abertos, e efetuados as mesmas contagens microbianas realizadas no material antes de ensilar, sendo também determinado o $\mathrm{pH}$ das silagens, utilizando-se um potenciômetro (ASSOCIATION OF OFFICIAL AGRICULTURAL CHEMISTS, 1975).

Para avaliação da composição bromatológica utilizou-se o mesmo processo, ou seja, foram coletadas amostras das partes da planta e da planta inteira antes de ensilar, e após a abertura dos silos, que foram submetidas à pré-secagem por 72 horas em estufa com ventilação forçada a $65^{\circ} \mathrm{C}$ e, em seguida, foram moídas em moinho tipo Willey. Foram determinados os teores de matéria seca (MS), proteína bruta $(\mathrm{PB})$, fibra em detergente neutra (FDN), fibra em detergente ácido (FDA) e hemicelulose (HEM) segundo metodologia citada por SILVA (1999).

Os dados foram submetidos à análise de variância e os valores médios dos constituintes bromatológicos, $\mathrm{pH}$ e as contagens microbianas, antes e após a ensilagem, foram comparados pelo teste de Tukey a 5\% de significância, utilizando-se o pacote estatístico SAEG-UFV (SISTEMA PARA ANÁLISES ESTATÍSTICAS E GENÉTICAS, 1999), versão 8,0.

\section{Resultados e Discussão}

$\mathrm{Na}$ Tabela 2 podem ser observados os valores médios do número de bactérias láticas, enterobactérias, fungos e leveduras nas diferentes partes da planta e na planta inteira antes de ensilar. O maior valor de bactérias láticas foi observado para o colmo das plantas (4,69 log ufc/g), seguido pela planta inteira $(4,32 \log \mathrm{ufc} / \mathrm{g})$, sendo que tanto a folha expandia quanto a folha em expansão apresentaram os menores valores destas bactérias. A folha 
expandida apresentou o maior valor de de um órgão de reserva, o colmo apresenta grande enterobactérias e de fungos e leveduras, 5,60 e 4,52 $\log \mathrm{ufc} / \mathrm{g}$, respectivamente. O menor valor da contagem de fungos e leveduras foi observado para o colmo, entretanto o menor valor de enterobactérias foi observado para a folha em expansão. Por se tratar quantidade de carboidratos solúveis, e no caso do presente experimento, um maior valor de matéria seca foi observado neste órgão, condições que, segundo MCDONALD (1981), favorecem o crescimento de bactérias produtoras de ácido lático.

Tabela 2. Número de bactérias (log ufc/g) láticas (BAL), enterobactérias (ENT) e fungos e leveduras (FeL) na folha em expansão, folha expandida, colmo e planta, antes da ensilagem.

\begin{tabular}{lccc}
\hline Separação botânica & BAL & ENT & FeL \\
\hline F. expansão & $3,81 \mathrm{~b}$ & $4,38 \mathrm{c}$ & $4,44 \mathrm{c}$ \\
F. expandida & $3,73 \mathrm{~b}$ & $5,60 \mathrm{a}$ & $4,52 \mathrm{a}$ \\
Colmo & $4,69 \mathrm{a}$ & $4,91 \mathrm{~b}$ & $4,32 \mathrm{~d}$ \\
Planta & $4,32 \mathrm{ab}$ & $4,52 \mathrm{c}$ & $5,08 \mathrm{~b}$ \\
CV $(\%)$ & 5,63 & 1,33 & 1,38
\end{tabular}

Médias seguidas pela mesma letra na mesma coluna não diferem, estatisticamente, pelo teste de Tukey, $5 \%$ de probabilidade.

Diferenças nas quantidades das populações de microrganismos refletiram em diferenças de contagens nas silagens, conforme pode ser observado na Tabela 3. Observa-se que não foram detectadas populações de enterobactérias e de fungos e leveduras nas silagens compostas somente por colmo. Por outro lado, a silagem de colmo foi a que apresentou o maior número de bactérias láticas $(8,51 \log u f c / g)$. Estes resultados podem explicar o menor valor de $\mathrm{pH}$ observado na silagem de colmo $(4,69)$. Enquanto que para as folhas em expansão, folha expandida e planta, os valores de pH foram, 5,20, 4,78 e 4,96, respectivamente. Considerando-se os valores de $\mathrm{pH}$, somente a silagem de colmo apresenta um $\mathrm{pH}$ ideal, segundo MCDONALD (1981). Os resultados evidenciam a grande importância de se incluir o colmo do capim-tanzânia, durante a ensilagem, como forma de garantir um perfil de fermentação favorável.

Tabela 3. Número de bactérias (log ufc/g) láticas (BAL), enterobactérias (ENT) e fungos e leveduras (FeL) e pH na folha em expansão, folha expandida, colmo e planta inteira das silagens.

\begin{tabular}{lcccc}
\hline Separação botânica & BAL & ENT & FeL & pH \\
\hline F. expansão & $7,84 \mathrm{~b}$ & $3,49 \mathrm{a}$ & $5,15 \mathrm{~b}$ & $5,20 \mathrm{a}$ \\
F. expandida & $7,09 \mathrm{~d}$ & $1,97 \mathrm{~b}$ & $5,65 \mathrm{ab}$ & $4,78 \mathrm{cb}$ \\
Colmo & $8,51 \mathrm{a}$ & $0,00 \mathrm{c}$ & $0,00 \mathrm{c}$ & $4,69 \mathrm{c}$ \\
Planta & $7,40 \mathrm{c}$ & $3,43 \mathrm{a}$ & $6,60 \mathrm{a}$ & $4,96 \mathrm{~b}$ \\
CV $(\%)$ & 0,61 & 3,43 & 6,60 & 7,20 \\
\hline
\end{tabular}

Médias seguidas pela mesma letra na mesma coluna não diferem, estatisticamente, pelo teste de Tukey, $5 \%$ de probabilidade.

As composições bromatológicas das partes da planta e da planta inteira antes de ensilar o capimtanzânia podem ser observadas na Tabela 4. O menor valor de MS foi observado na folha em expansão $(20,88 \%)$, o que era se esperar, pois, a folha em expansão está no processo de crescimento, caracterizado pelo alongamento e divisão celular e por isso rica em água e com baixos teores de fibra. O maior valor de MS foi encontrado na folha senescente $(40,73 \%)$, que já sofreu boa parte da 
desidratação, principalmente pela translocação dos nutrientes para outras partes da planta e pela própria perda via estomática, pois as células quardas têm a tendência de ficar semi-aberta, quando a folha finaliza seu ciclo de vida (BIRCHAM; HODGSON, 1984; LEMAIRE; CHAPMAN, 1996). Zanine et al., (2003) avaliando o capim-tanzânia cortado aos 54 dias obtiveram valor de matéria seca da planta inteira de $20,9 \%$. No presente trabalho houve uma superioridade dessa variável 29,98\%, com o corte aos 60 dias.

Foi observada diferença estatística $(\mathrm{p}<0,05)$ para os teores de PB nas frações das plantas e na planta inteira. Os maiores valores foram verificados nas folhas em expansão e expandida, e os menores valores nas folhas em senescência e no colmo. Rego et al., (2003) trabalhando com manejo do capimtanzânia, observaram um teor de PB das lâminas foliares (folhas em expansão e expandidas) próximo aos $16,73 \%$. No presente experimento houve uma superioridade de teor de PB das lâminas foliares (20,16\%). Para o teor de PB do colmo os valores observados no presente experimento foram de 7,61\%, valores inferiores aos 9,5\% do experimento de Rego et al., (2003) e superiores aos resultados de Zanine et al., (2003) que foram de 3,9\% para a planta inteira.

Para os teores de FDN e FDA, os menores valores foram observados nas folhas em expansão e expandida, caracterizando a melhor qualidade da fibra nesses órgãos das plantas. O colmo e as folhas senescentes, obtiveram os maiores teores, justamente por possuírem fibra de menor degradação. A planta inteira apresentou valores médios de FDN e FDA, na ordem de $63 \%$ e $32,92 \%$, respectivamente. Já para a HEM não foi observada diferença estatística ( $>0,05)$ para os órgãos da planta e a planta inteira, com valores médios de $30 \%$. No presente experimento foi registrado uma média das folhas em expansão e expandidas de 58,85\% para a FDN e $28,40 \%$ para a FDA. Resultados inferiores aos observados por Rego et al., (2003) que divulgaram valores médios de FDN para as lâminas foliares de $65 \%$, e para a FDA de $55 \%$. O que pode ser explicado pela idade inferior de corte do capim do presente experimento que foi de 60 dias. Gerdes et al., (2000) avaliando diversas espécies de Panicum maximum, incluindo o capim-tanzânia, também constataram maiores teores de FDN e FDA, que no presente experimento.

Barbosa e Euclides (1996), observaram médias de $70,9 \%$ e $78,6 \%$ para os teores de FDN de folhas e colmos, respectivamente. Enquanto, Rego et al., (2003) observaram valores médios de FDN para o colmo de $80 \%$. Resultados estes superiores aos do presente experimento. Resultados inferiores para os teores de FDN e superiores para a PB foram observados no presente experimento em relação aos resultados relatados por Difante (2005) avaliando o capim-tanzânia que observou valores médios para FDN de 76,6, 78,8 e 78,5\% e PB de 10,63, 6,69 e $5,69 \%$ para lâminas foliares, colmo e material morto (folhas mais colmo senescente), respectivamente.

Tabela 4. Teores de matéria seca (MS), proteína bruta (PB), fibra em detergente neutro (FDN), fibra em detergente ácido (FDA) e hemicelulose na folha em expansão, folha expandida, folha senescente, colmo e planta, antes da ensilagem.

\begin{tabular}{lccccc}
\hline Separação botânica & MS & PB & FDN & FDA & HEM \\
& $(\%)$ & $(\%)$ & $(\%)$ & $(\%)$ & $(\%)$ \\
\hline F. expansão & $20,88 \mathrm{c}$ & $17,45 \mathrm{a}$ & $57,06 \mathrm{c}$ & $27,69 \mathrm{e}$ & $29,37 \mathrm{a}$ \\
F. expandida & $19,44 \mathrm{~d}$ & $16,85 \mathrm{~b}$ & $60,59 \mathrm{c}$ & $29,12 \mathrm{~d}$ & $31,47 \mathrm{a}$ \\
F. senescente & $40,73 \mathrm{a}$ & $6,24 \mathrm{e}$ & $66,92 \mathrm{a}$ & $36,23 \mathrm{~b}$ & $30,69 \mathrm{a}$ \\
Colmo & $13,12 \mathrm{e}$ & $7,61 \mathrm{~d}$ & $63,29 \mathrm{~b}$ & $37,90 \mathrm{a}$ & $25,39 \mathrm{a}$ \\
Planta & $29,98 \mathrm{~b}$ & $10,81 \mathrm{c}$ & $63,00 \mathrm{~b}$ & $32,92 \mathrm{c}$ & $30,08 \mathrm{a}$ \\
CV (\%) & 1,27 & 1,60 & 3,98 & 0,42 & 8,31 \\
\hline
\end{tabular}

Médias seguidas pela mesma letra na mesma coluna não diferem, estatisticamente, pelo teste de Tukey, $5 \%$ de probabilidade. 
Com relação aos valores nutricionais dos diferentes órgãos da planta e da planta inteira após o processo de ensilagem, podem ser observados na Tabela 5.

O maior valor de MS, foi verificado na silagem da planta inteira $(31,59 \%)$ e o menor na silagem de colmo $(18,44 \%)$ por se tratar de um órgão rico em reserva de carboidratos solúveis para a planta e principalmente, por estar em um estágio de desenvolvimento precoce (60 dias). Os maiores teores de PB, foram observados nas silagens de folhas em expansão e expandidas. E o menor teor de PB foi na silagem de colmo, embora tenha sido observado valores de PB extremamente significantes (7,31\%), isso devido ao período de corte que proveu colmo novo, que como discutido anteriormente é importante para o crescimento de microrganismo desejáveis para fermentação do material ensilado e se a planta for manejada corretamente produz colmo com considerável valor de $\mathrm{PB}$, além de fibra de boa qualidade. Rodrigues et al., (2001) avaliando a silagem de capim-elefante (Penisetum purpureum) cortada aos 70 dias observaram valores de MS e PB na planta inteira de 17,11 e $21,30 \%$, respectivamente. Os resultados do presente experimento foram superiores aos teores MS e PB em relação aos observados por Ferreira et al., (2005) em silagem de capim-mombaça (Panicum maximum) que verificaram teores de MS e PB na planta inteira de 17,69 e 7,71\%, respectivamente.

Os maiores teores de FDN e FDA, foram observados na silagem de colmo $(64,58$ e $39,70 \%$, respectivamente) e os menores teores nas silagens das folhas em expansão (47,86 e 27,08\%, respectivamente). Os resultados do presente experimento foram inferiores aos resultados de Rodrigues et al., (2001) que verificaram teores de FDN e FDA na silagem de planta inteira de 76,24 e $53,88 \%$, respectivamente. IGARASI (2001) que obteve valores de FDN e FDA de 67,7 e 45,8\%, respectivamente, em silagem da planta inteira de capim-tanzânia. Bergamaschine, Isepon e Guatura, (2000) que relataram valores de 74,7 e $50,7 \%$ de FDN e FDA em silagens de planta inteira de capimtanzânia. Coan, Silveira e Bernardes, (2001) que encontraram valores de 79 e 49,5\%, respectivamente, para silagem de capim-tanzânia com 60 dias de crescimento vegetativo. Ferreira et al., (2005) que relataram valores de 66,71 e $44,54 \%$ para os valores de FDN e FDA da silagem da planta inteira.

Quando se compara os órgãos da planta e a planta inteira antes e após ensilar, percebe-se que não houve profundas modificações no âmbito nutricional, talvez uma leve tendência à melhora das fibras do capim depois de ensilado. O que vale ressaltar, é que de acordo com o NRC (1996) é recomendado $8,5 \%$ de PB na MS para bovinos em manutenção e 10,7\% para obter $0,7 \mathrm{~kg}$ de ganho por dia, em função disto, os valores observados das folhas em expansão, expandidas e a planta inteira (lâmina mais colmo) do capim-tanzânia, são considerados satisfatórios para obter-se bom desempenho dos animais.

Tabela 5. Teores de matéria seca (MS), proteína bruta (PB), fibra em detergente neutro (FDN), fibra em detergente ácido (FDA) e hemicelulose (HEM) da silagem de capim-tanzânia nas diferentes partes da planta e na planta inteira.

\begin{tabular}{|c|c|c|c|c|c|}
\hline Separação botânica & $\begin{array}{l}\text { MS } \\
(\%)\end{array}$ & $\begin{array}{l}\text { PB } \\
(\%)\end{array}$ & $\begin{array}{c}\text { FDN } \\
(\%)\end{array}$ & $\begin{array}{c}\text { FDA } \\
(\%)\end{array}$ & $\begin{array}{c}\text { HEM } \\
(\%)\end{array}$ \\
\hline F. expansão & $23,93 \mathrm{c}$ & $16,43 b$ & $47,86 \mathrm{c}$ & $27,08 \mathrm{~d}$ & $20,78 b$ \\
\hline F. expandida & $26,80 \mathrm{~b}$ & $17,19 \mathrm{a}$ & $56,11 \mathrm{~b}$ & $29,18 \mathrm{c}$ & $26,93 \mathrm{a}$ \\
\hline Colmo & $18,44 d$ & $7,31 d$ & $64,58 \mathrm{a}$ & $39,70 \mathrm{a}$ & $24,88 \mathrm{ab}$ \\
\hline Planta & $31,59 \mathrm{a}$ & $13,69 \mathrm{c}$ & $57,74 \mathrm{~b}$ & $29,70 b$ & $28,04 \mathrm{a}$ \\
\hline CV (\%) & 1,93 & 0,71 & 2,36 & 0,28 & 5,18 \\
\hline
\end{tabular}

Médias seguidas pela mesma letra na mesma coluna não diferem, estatisticamente, pelo teste de Tukey, $5 \%$ de probabilidade. 


\section{Conclusões}

As populações microbianas são variáveis em função do órgão da planta, e o colmo é o órgão que assegura o crescimento de bactérias láticas e inibição do crescimento de microrganismos indesejáveis durante a ensilagem do capim-tanzânia.

No âmbito nutricional, existe uma hierarquia decrescente do valor bromatológico: folha em expansão, folha expandida, planta inteira e colmo antes e após o processo de ensilagem.

\section{Referências bibliográficas}

ASSOCIATION OF OFFICIAL AGRICULTURAL CHEMISTS - AOAC. 1975. Official methods of analysis. $12^{\text {th }}$ ed. Washington DC, USA: Association of Official Agricultural Chemists, 1975. 1298p.

ÁVILA, C. L. S.; PINTO, J .C.; EVANGELISTA, E. R.; MORAIS, E. R.; TAVARES, V. B. Perfil de fermentação das silagens de capim-tanzânia com aditivos teores matéria seca e proteína bruta. In: REUNIÃO ANUAL DA SOCIEDADE BRASILEIRA DE ZOOTECNIA, 40., 2003, Santa Maria. Anais... Santa Maria: UFSM, 2003. CD ROM.

BARBOSA, R. A.; EUCLIDES, V. P. B. Valores nutritivos de três ecotipos de Panicum maximum Jacq. In: REUNIÃO ANUAL DA SOCIEDADE BRASILEIRA DE ZOOTECNIA, 33., 1996, Fortaleza. Anais... Fortaleza: Sociedade Brasileira de Zootecnia, 1996. p.106-108.

BERGAMASCHINE, A. F.; ISEPON, O. J.; GUATURA, A. Efeito da adição de resíduo de milho e da cultura enzimobacteriana sobre a qualidade da silagem de capim-tanzânia. In: REUNIÃO ANUAL DA SOCIEDADE BRASILEIRA DE ZOOTECNIA, 37., 2000, Piracicaba. Anais... Piracicaba: FEALQ, 2000. CD ROM.

BIRCHAM, J. S.; HODGSON, J. The effects of change in herbage mass on rates of herbage growth and senescence in mixed swards. Grass and Forage Science, Oxford, v.39, n.2, p.111-115, 1984.

COAN, R. M.; SILVEIRA, R. E. N.; BERNARDES, T. F. Efeito do inoculante bacteriano sobre a composição química, digestibilidade e qualidade das silagens de capins-tanzânia e mombaça. In: REUNIÃO ANUAL DA SOCIEDADE BRASILEIRA DE ZOOTECNIA, 38., 2001, Piracicaba. Anais... Piracicaba: FEALQ, 2001. p.124-125.
DIFANTE, G. S. Desempenho de novilhos, comportamento ingestivo e consumo voluntário em pastagem de capim Panicum máximum cv tanzânia. 2005. Tese (Doutorado) Universidade Federal de Viçosa, Viçosa. 84p.

FERREIRA, D. J.; ZANINE, A. M.; SANTOS, E. D.; ALMEIDA, J. C. A.; PEREIRA, O. G. Avaliação da produção e composição bromatológica de silagem de capim mombaça com farelo de trigo. In: JORNADA DE INICIAÇÃO CIENTÍFICA, 15., 2005, Rio de Janeiro. Anais... Rio de Janeiro: UFRRJ, 2005. CD ROM.

FILYA, I.; SUCU, E.; KARABULUT, A. The effect of Propionibacterium acidipropionici, with or without Lactobacillus plantarum, on the fermentation and aerobic stability of wheat, sorghum and maize silages. Journal of Applied Microbiology, Oxford, v.97, p.818-826, 2004.

GERDES, L.; WERNER, J. C.; COLOZZA, M. T.; POSSENTI, R. A; SCHAMMASS, E. A. Avaliação de características das gramíneas forrageiras Marandu, Setária e Tanzânia nas estações do ano. Revista Brasileira de Zootecnia, Viçosa, v.29, n.4, p.955-963, 2000.

IGARASI, M. S. Controle de perdas na ensilagem de capim tanzânia (panicum maximum jacq. cv. tanzânia) sob os efeitos do teor de matéria seca, do tamanho de partícula, da estação do ano e da presença do inoculante bacteriano. 2002. Dissertação (Mestrado) - Escola Superior "Luiz de Queiroz”, Universidade de São Paulo, Piracicaba, 2002. $64 \mathrm{p}$.

JANK, L. Potencial do gênero Panicum. SIMPÓSIOS BRASILEIROS DE FORRAGEIRAS E PASTAGENS, 1. Campinas. Anais... Campinas: SBNA, 1994. p.25-31

LEMAIRE, G., CHAPMAN, D. Tissue flows in grazed plants communities. In: HODGSON, J., ILLIUS, A.W. (Ed.). The ecology and managment of grazing systems. Wallingford, UK: CAB INTERNATIONAL, 1996. p.3-36.

McDONALD, P.J. The biochemistry of silage. New York: John Wiley e Sons, 1981.218p.

McDONALD, P. J.; HENDERSON, A. R.; HERON, S. J.E. The biochemistry of silage. 2.ed. Mallow: Chalcombe Publications, 1991.340p.

REGO, F. C. A.; CECATO, U.; DAMASCENO, J.C.; RIBAS, N. P.; SANTOS, G. T.; MOREIRA, F. B.; RODRIGUES, A. M. Valor nutritivo do capim-Tanzânia (Panicum maximum Jacq cv. Tanzânia-1) manejado em alturas de pastejo. Acta Scientiarum. Animal Sciences, Maringá, v.25, n.2, p.363370, 2003. 
RODRIGUES, P. H. M.; ANDRADE, S. J. T.; FERNANDES, T.; LIMA, F. R.; METOLLI, L.; LUCCI, C. S. Valor nutritivo da silagem de capim-elefante cultivar Napier (Pennicetum purpureum, Shum) inoculado com bactérias ácido-lácticas. Acta Scientiarium. Animal Sciences, Maringá, v.23, n.4, p.809-813, 2001.

SILVA, F. C. Manual de análises químicas de solos, plantas e fertilidades. Rio de Janeiro: CNPS, 1999. 235p.

SISTEMA DE ANÁLISES ESTATÍSTICAS E GENÉTICAS - SAEG - Universidade Federal de Viçosa - UFV. Viçosa: Universidade Federal de Viçosa, 1999. Manual do usuário, (Versão 8.0).
WEINBERG, Z. G.; MUCK. R. E. New trends and opportunities in the development and use of inoculants for silage. Journal of Applied Microbiology, Oxford, v.19, p.53-68, 1996.

WOOLFORD, M. K. The silage fermentation. New York: Marcel Dekker, 1984. p.23-132.

WRIGHT, D. A.; GORDON, F. J.; STEEN, R. W. J.; PATTERSON, D. C. Factors influencing the response in intake of grass before ensiling: A review. Grass and Forage Science, Oxford, v. 55, p.1-13, 2000.

ZANINE, A. M.; SCHIMIDT, L. T.; DIAS, P. F.; MANHÃES SOUTO, S. M. Produção e qualidade do capim Tanzânia (Panicum maximum) em diferentes idades e adubado com doses de N de chorume bovino. Pasturas Tropicales, Cali, v.26, n.2, p.30-36, 2003. 